\title{
CVDに及ぼす気相および表面反応の影響に関する一考察 ${ }^{\dagger}$
}

\author{
佐藤恒之・今石宣之
}

\section{九州大学 機能物質科学研究所 ${ }^{\dagger \dagger}$}

近年, CVD法による薄膜や微粒子の作成技術は半導体 製造プロセス，表面好理あるいはセラミックス原料製造 など広範な分野において利用されている。しかし，CVD 装置の一般的な解析法および設計基準は未だ確立されて おらず，個々のケースにあわせ経験的に設計・操作され ているのが現状である.

管型 CVD 反応器内における成膜機構については，稲 垣ら ${ }^{1)}$ が実験より得られた成膜速度分布を基に，気相反 応生成物が管壁に拡散して堆積するという逐次過程モデ ルを提出している. しかし成膜速度分布に関与する因子 は多く, 成膜速度分布から気相反応速度を導出しようと する彼らの方法の妥当性を検討する必要がある。乙こで は簡単な数学モデルを用いて，種々の速度場あるいは温 度場を想定し，その中で成膜速度分布に及ぼす気相招よ び表面反応の影響を考察した。

\section{1. 基 礎 式}

きわめて簡略化した 2 次元問題を考える. このとき仮 定として,

（i）管型反応器内では十分発達した層流速度分布が維 持されている.

(ii) エネルギーおよび物質収支式中の軸方向の拡散は 無視する.

(iii) 物性値は一定であり，熱拡散は無視し得る。また 気相中のソースガス濃度は低く，多くのMOCVDで見ら れるように大量のキャリアーガスで薄められているもの とする.

(iv) ソースガス A は気相中で熱分解して B となり， B が基板へ拡散して 1 次界面反応を経て析出する.

(v) 成膜速度は界面反応速度に等しい。

をおくと，無次元基礎式としてEqs.(1)〜（4) を得る.

$$
\begin{aligned}
& \frac{\partial T}{\partial X}=\frac{L e}{2\left(1-R^{2}\right)}\left(\frac{\partial^{2} T}{\partial R^{2}}+\frac{1}{R} \frac{\partial T}{\partial R}\right) \\
& \frac{\partial C_{A}}{\partial X}=\frac{1}{2\left(1-R^{2}\right)}\left(\frac{\partial^{2} C_{A}}{\partial R^{2}}+\frac{1}{R} \frac{\partial C_{A}}{\partial R}\right)
\end{aligned}
$$

† 1989 年 9 月 5 日

† 7816 春日市春日公園6-1

* 仮定 (ii) を置いたため, 本解析はPeclet数 $\left(\equiv \frac{\leq u>r_{0}}{D_{A}}\right)$ の値が大きい場合のみ適用すべきである.

$$
\begin{gathered}
-\frac{K}{2\left(1-R^{2}\right)} \exp \left\{\frac{-\Delta E_{R}(1-T)}{R_{g} T}\right\} C_{A} \\
\frac{\partial C_{B}}{\partial X}=\frac{E}{2\left(1-R^{2}\right)}\left(\frac{\partial^{2} C_{B}}{\partial R^{2}}+\frac{1}{R} \frac{\partial C_{B}}{\partial R}\right) \\
+\frac{K}{2\left(1-R^{2}\right)} \exp \left\{\frac{-\Delta E_{R}(1-T)}{R_{g} T}\right\} C_{A} \\
x=0 ; T=\left(\frac{t_{0}}{t_{H}}\right), \quad C_{A}=1.0, \quad C_{B}=0 \\
R=0 ; \frac{\partial T}{\partial R}=0, \frac{\partial C_{A}}{\partial R}=0, \frac{\partial C_{B}}{\partial R}=0 \\
R=1 ; T=1, \quad \frac{\partial C_{A}}{\partial R}=0,-\frac{\partial C_{B}}{\partial R}=\frac{K_{S B}}{E} C_{B}
\end{gathered}
$$

Eq. (5)に無次元化に際し用いた無次元変数を示す.

$$
\begin{aligned}
& R=\frac{r}{r_{0}}, \quad L e=\frac{\kappa}{D_{A}}, \quad E=\frac{D_{B}}{D_{A}}, \quad C_{A}=\frac{c_{A}}{c_{A 0}}, \\
& C_{B}=\frac{c_{B}}{c_{A 0}}, \quad X=\frac{D_{A} x}{<u>r_{0}^{2}}, \quad K=\frac{r_{0}^{2} k_{0}\left(\frac{-\Delta E_{R}}{R_{g} t_{H}}\right)}{D_{A}}, \\
& K_{S B}=\frac{r_{0} K_{S B}}{D_{A}}
\end{aligned}
$$

以上の方程式を有限差分化し, Crank-Nicholson法に より数値解を得た.

なお計算にあたって，Le=2.66, およびおおかたの場 合 $E=1.7$ を用いだ .

\section{2. 計算結果亡考察}

\section{$2 \cdot 1$ 成膜速度分布に及ぼす $K$ の影響}

いま，等温で操作圧をかえてもキャリアガスおよび成 分 $\mathrm{A}$ の質量流量が一定に保たれている場合を考える.乙 のとき，Le,Eなどのパラメータ値は一定となる．一方， $K$ の分母には $D_{A}$ があり，压力の低下とともに $K$ は減少す る.

Fig. 1 (A) に放物線速度場において $K_{S B}$ を $1 \times 10^{7}$ 一定 とし，Kのみを種々変化させた場合の軸方向成膜速度 $(G R)$ 分布, 平均温度 $(\bar{T})$ 分布ならびに各成分の平均濃 度 $\left(\overline{C_{A}}, \overline{C_{B}}\right)$ 分布を示す. ただし成膜速度, 平均温度およ び平均濃度はそれぞれ次式

$$
\begin{aligned}
& G R(X)=-\left.E \frac{\partial C_{B}}{\partial R}\right|_{R=1} \equiv \frac{N_{B} r_{0}}{D_{A} c_{A 0}} \\
& \bar{T}=\frac{2 \pi \int_{0}^{1} R U T d R}{2 \pi \int_{0}^{1} R U d R}
\end{aligned}
$$




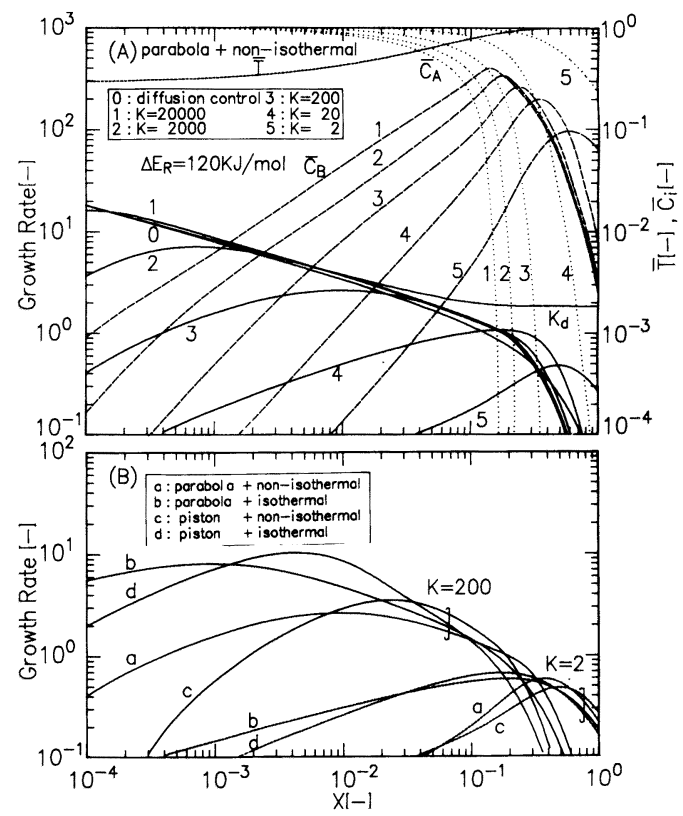

Fig. 1 Effect of $K$ on the distribution of the local growth rate and the cup-mixing concentration in the direction of flow axis

$$
\overline{C_{i}}=\frac{2 \pi \int_{0}^{1} R U C_{i} d R}{2 \pi \int_{0}^{1} R U d R}(i=A, B)
$$

で与えられる。

キー0で示される実線は気相内反応を無視した場合 （A が拡散して，高温面上で分解析出する場合）の成膜 速度分布であり， $X=0$ では無限大に発散する。また $X>$ 0.2 で急激に減少しているのは平均濃度の指数関数的な 减少が原因で，乙の領域では無次元物質移動係数 $K_{d}(\equiv$ $\left.k_{d} r_{0} / D_{A}=N_{A} r_{0} /\left(D_{A} \overline{C_{A}}\right)\right)$ はほぼ一定である. 気相内反応 は有限の速度で進行するため, $X=0$ での成膜速度の発散 はなくなるが，Xの小さい領域で最大值を示す，Kの減 少 (操作圧の低下による $C_{A 0}$ の減少と $D_{A}$ の増加あるいは 操作温度の低下）にともないBの生成速度も減少し, 成 膜速度が最大を示す $X$ の值は下流へと移動する。

Fig. 1(B) に, ピストン流れ+等温, ピストン流れ+非 等温抢よびパラボラ流れ+等温条件下における各成膜速 度分布を比較して示す. 成膜速度分布は両対数グラフ上 で見るかぎり，速度分布，温度分布によって明白な相違 がみられる，乙のことは成膜速度分布を予測する上で， 流れ場や温度場を十分考慮に入れるべきことを示唆して いる.

Fig. 2 にパラボラ流れ条件下において，壁温を変化さ せた場合の成膜速度分布を示す．乙の場合， $k_{0}$ を変化さ せることにより同一の $K$ を与えることができる．系内の

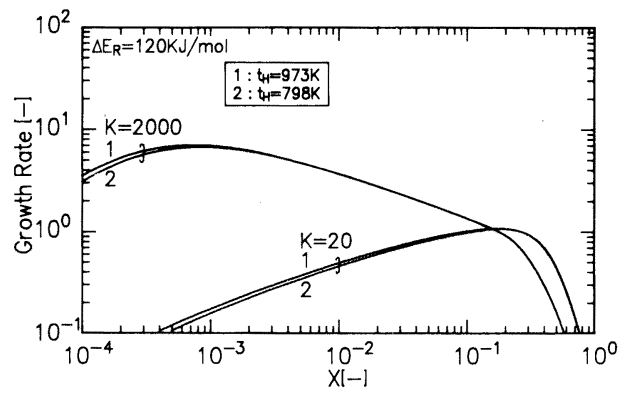

Fig. 2 Effect of temperature on the distribution of the local growth rate in the direction of flow axis

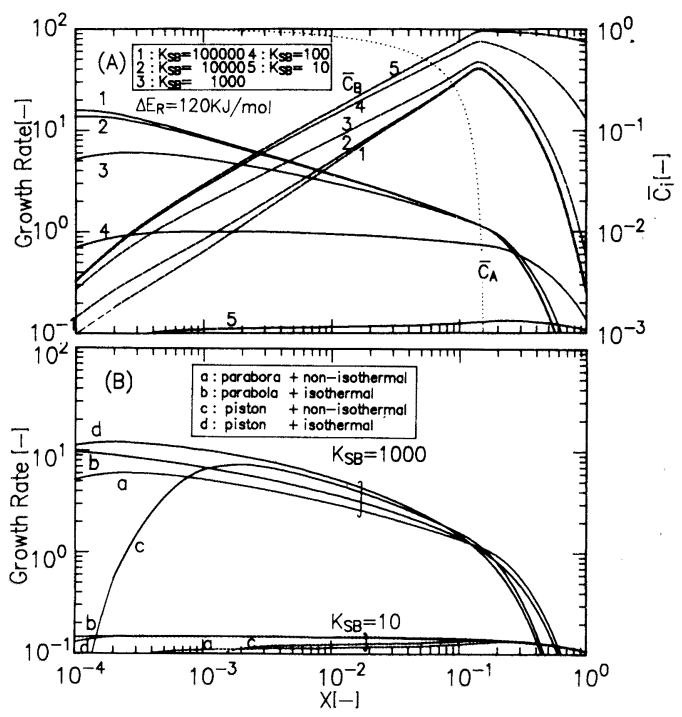

Fig. 3 Effect of $K_{S B}$ on the distribution of the local growth rate and the cup-mixing concentration in the direction of flow axis

温度が変化するため成膜速度には若干の変化がみられる が，約 $10 \%$ 程度以内で同じ傾向を示すととがわかる.

\section{$2 \cdot 2$ 成膜速度に及ぼす $\boldsymbol{K}_{S B}$ の影響}

$K_{S B}$ の值は $K$ と同様に, 界面反応速度定数，操作温度 および操作圧力によって変化する．系の圧力が低下する 之拡散係数の増加から $K_{S B}$ の值は減少する。

Fig. 3(A) にパラボラ流れにおいて $K=20000$ 一定とし， $K_{S B}$ のみを变化させた場合の計算例を示す． $K_{S B}$ の值が 比較的大きい場合には成膜速度はFig.1(A) 之同様，入口 近傍で大きな值を有している。 $K_{S B}$ が減少するに従って 膜厚分布はかなり平坦化される（表面反応律速）。ただ し成膜速度そのものは $K_{S B}$ の減少とともに全体的に著し く小さくなっている.

(B) 図に, 速度分布および温度分布条件を種々変化さ せた場合の成膜速度分布を示す. 


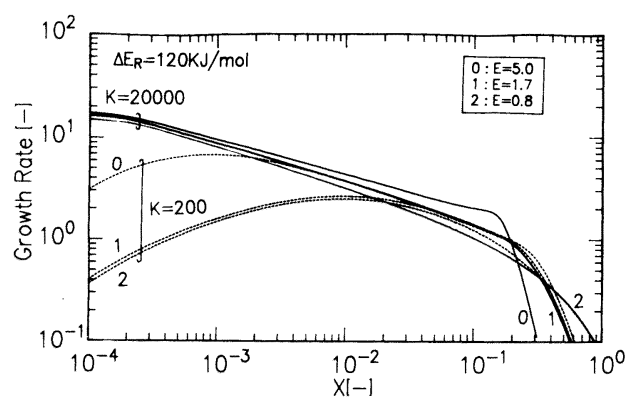

Fig. 4 Effect of $E$ on the distribution of the local growth rate in the direction of flow axis

\section{$2 \cdot 3$ 成膜速度に及ぼす $E$ の影響}

Fig. 4 にパラボラ流れ＋非等温条件下において $E$ を変 化させた場合の成膜速度分布を示す． $E$ が大きいほど成 膜速度は大きいが， Bの消費も早くなるため $X$ の大きい 領域で成膜速度は急速に減少する。

\section{4 既往のモデルとの成膜速度の比較}

等温管型反応器における䅧垣ら”のモデルによる成膜 速度式を次式

$$
\begin{aligned}
& G R(X)=\frac{K \cdot \overline{K_{d}}}{\left(2 \overline{K_{d}}-K\right)}\left\{\exp ^{-K X}-\exp ^{-2 \bar{K}_{d} X}\right\} \\
& \text { ただし } \overline{K_{d}}=\frac{k_{d} \cdot R}{D_{A}}
\end{aligned}
$$

のごとく，本シミュレーションにおける無次元成膜速度 $G R(X)$ に合致するよう変形する. シミュレーションより 得ら机た成膜速度との差の 2 乗和を最小にする $K$ と $\overline{K_{d}}$ の 組み合せをMarquardt 法により求め, その際得られた 最大成膜速度を本モデルシミュレーション值と比較する. 最適化により得られた $K$ および $\bar{K}_{d}$ (三平均 $S h$ 值) の值を Table 1 亿示す. $\overline{K_{d}}$ の值は円管内層流の平均 $S h$ 数之同 オーダーであり, 気相生成物拡散に関してはほぼ稲垣ら の推定どおりと思われる. しかし気相反応に直接関与す るKK関してはシミュレーション時に使用した值と約 0.2〜 40倍あの開きがある.乙のことは稲垣らのモデル の適用性に限界のあることを示している。したがって， $\mathrm{CVD}$ 気相反応機構を考察するには, 成膜速度分布のみ ならず，温度および濃度などの測定量も十分考慮にいれ た総合的考察が必要である.

[謝 辞] 本研究は平成元年度文部省科学研究費補助金 総合研究 A (研究課題: 熱CVD装置のシミュレーション, 課 題番号：01303009）の一部として行われたものである. 付記し て謝意を表する。
Table 1 Optimum parameters obtained by the

\begin{tabular}{|c|c|c|c|}
\hline & \multicolumn{2}{|c|}{$\begin{array}{c}K \\
\ldots \ldots \\
\end{array}$} & \multirow{2}{*}{$\begin{array}{c}\overline{K_{d}} \\
\ldots \ldots \ldots \ldots \\
\text { optimum }\end{array}$} \\
\hline & simulation & optimum $\vdots$ & \\
\hline \multirow{8}{*}{$\begin{array}{c}\text { parabola } \\
+ \\
\text { non-isothermal }\end{array}$} & 2.0 & 5.2 & 1.1 \\
\hline & 20.0 & 3.6 & 8.5 \\
\hline & 200.0 & 1004.9 & 2.6 \\
\hline & 2000.0 & 10454.0 & 6.0 \\
\hline & 58.0 & 44.4 & 1.6 \\
\hline & 491.0 & 748.4 & 2.7 \\
\hline & 7810.0 & 9587.8 & 6.5 \\
\hline & 39000.0 & 8307.4 & 12.3 \\
\hline \multirow{3}{*}{$\begin{array}{c}\text { parabola } \\
+ \\
\text { isothermal }\end{array}$} & 2.0 & 30.1 & 0.7 \\
\hline & 20.0 & 787.6 & 2.7 \\
\hline & 200.0 & 1002.4 & 2.6 \\
\hline \multirow{3}{*}{$\begin{array}{c}\begin{array}{c}\text { piston } \\
+ \\
\text { non-isothermal }\end{array} \\
\text { n. }\end{array}$} & 2.0 & 7.9 & 0.7 \\
\hline & 20.0 & 12.5 & 2.3 \\
\hline & 200.0 & 268.2 & 4.0 \\
\hline \multirow{3}{*}{$\begin{array}{c}\text { piston } \\
+ \\
\text { isothermal }\end{array}$} & 2.0 & 22.2 & 0.9 \\
\hline & 20.0 & 131.0 & 3.7 \\
\hline & 200.0 & 1456.8 & 10.4 \\
\hline
\end{tabular}
Marquard method

\section{Nomenclature}

$C_{i}=$ nondimensional concentration of species $i[-]$

$c_{i}=$ concentration of species $i \quad\left[\mathrm{~mol} / \mathrm{m}^{3}\right]$

$D_{i}=$ diffusion coefficient of species $i \quad\left[\mathrm{~m}^{2} / \mathrm{s}\right]$

$d=$ diameter [m]

$E=$ ratio of diffusion coefficient $\quad[-]$

$\Delta E_{R}=$ activation energy $\quad[\mathrm{kJ} / \mathrm{mol}]$

$G R=$ nondimensional growth rate $\quad[-]$

$K=$ nondimensional gas phase reaction rate const.

$K_{S}=$ nondimensional surface reaction rate const.

$K_{d}=$ nondimensional local mass transfer coefficient

$k_{d}=$ mass transfer coefficient

$k_{0}=$ frequency factor

$k_{i}=$ surface reaction rate const. of species $i[\mathrm{~m} / \mathrm{s}]$

Le = Lewis number

$N_{i}=$ mass flux of species $i$ onto tube wall

$\left[\mathrm{mol} /\left(\mathrm{m}^{2} \cdot \mathrm{s}\right)\right]$

$R$ = nondimensional radial distance

$R_{g}=$ gas constant

$[\mathrm{kJ} /(\mathrm{mol} \cdot \mathrm{K})]$

$r$ = radial distance

$r_{0}=$ radius

$T=$ nondimensional temperature 


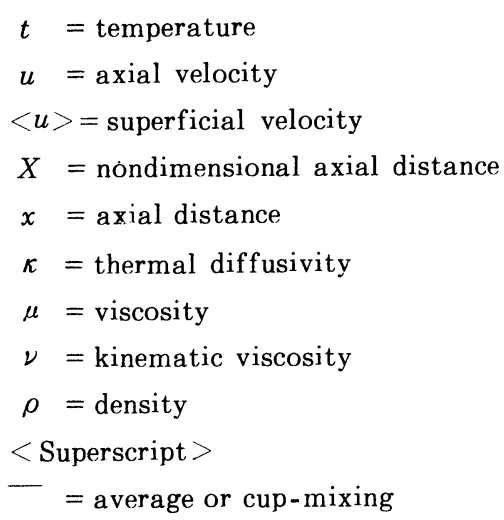

$$
\begin{aligned}
{[\mathrm{K}] } & <\text { Subscripts }> \\
{[\mathrm{m} / \mathrm{s}] } & \mathrm{H}=\text { heating wall } \\
{[\mathrm{m} / \mathrm{s}] } & \mathrm{O}=\text { inlet } \\
{[-] } & \mathrm{A}=\text { species } A \\
{[\mathrm{~m}] } & \mathrm{B}=\text { species } \mathrm{B} \\
{\left[\mathrm{m}^{2} / \mathrm{s}\right] } &
\end{aligned}
$$$$
[\mathrm{kg} /(\mathrm{m} \cdot \mathrm{s})]
$$$$
\left[\mathrm{m}^{2} / \mathrm{s}\right]
$$$$
\left[\mathrm{kg} / \mathrm{m}^{3}\right]
$$

\section{Literature cited}

1) Inagaki, T. and H. Komiyama: Kagaku Kogaku Ronbunshuu, 15, 849 (1989)

\title{
The Effects of Gas Phase and Surface Chemical Reactions on Film Growth Rate in a Tubular CVD Reactor
}

\author{
Tsuneyuki Sato and Nobuyuki Imaishi
}

Institute of Advanced Material Study, Kyushu Univ. Fukuoka 816

Key Words : CVD, Gas Phase Reaction, Surface Reaction, Film Growth Rate, Tubular Reactor

The effects of gas phase and surface chemical reactions on film growth rates were numerically studied, using a tubular CVD reactor model. The model consists of the energy and mass transport equations in fully developed laminar flows with constant wall temperature.

The uniformity of film thickness was found to be improved under the rate-determining steps of elther gas-phase or surface reactions. However, the growth rates became rather small.

The two-parameter model proposed by Inagaki et al. was examined, using our model, in terms of growth rate distributions. The parameter of the gas-phase reaction obtained by Inagaki et al. did not agree with ours. 